\title{
Moving Beyond Poverty: \\ Neighborhood Structure, Social Processes, and Health*
}

\author{
CHRISTOPHER R. BROWNING
}

The Ohio State University

KATHLEEN A. CAGNEY

University of Chicago

Journal of Health and Social Behavior 2003, Vol 44 (December): 552-571

We investigate the impact of neighborhood structural characteristics, social organization, and culture on self-rated health in a large, cross-sectional sample of urban adults. Findings indicate that neighborhood affluence is a more powerful predictor of health status than poverty, above and beyond individual demographic background, socioeconomic status, health behaviors, and insurance coverage. Moreover, neighborhood affluence and residential stability interact in their association with health. When the prevalence of affluence is low, residential stability is negatively associated with health. Neighborhood affluence also accounts for a substantial proportion of the racial gap in health status. Finally, collective efficacy is a significant positive predictor of health but does not mediate the effects of structural factors.

Research on the contribution of neighborhood characteristics to individual health has progressed rapidly over the last decade. Mounting empirical evidence of neighborhood socioeconomic structure (SES) effects on a range of adult outcomes including mortality (Haan, Kaplan, and Camacho 1987), heart disease (LeClere, Rogers, and Peters 1998), number of chronic conditions (Robert 1998), and self-rated health (Malmstrom, Sundquist, and Johansson 1999) has fueled calls for continued research on the health effects of multiple dimensions of community SES and the mechanisms that may account for the community structure-health link (Robert 1999). Despite

* Paper presented in part at the 2001 meetings of the Population Association of America, Washington, D.C. Support for this research was provided by the Ohio State Seed Grand Initiative. Thanks to Felicia LeClere, Lauren Krivo, Ming Wen, and participants in the University of Chicago Population Research Center Demography Workshop for their helpful comments. We wish to thank Robert Sampson, Felton Earls, and members of the Project on Human Development in Chicago neighborhoods for generously providing access to the Community Survey data. We also thank the Metropolitan Community Information Center for providing access to the Metro Survey data. these efforts, neighborhood effects research on health has typically focused on only one dimension of neighborhood structure-the prevalence of economic deprivation - and has yet to explore competing hypotheses regarding the community level mediators of structural effects on health.

We draw on social disorganization and collective efficacy theory (Shaw \& McKay 1969; Sampson, Raudenbush, and Earls 1997), Wilson's theory of neighborhood decline (Wilson 1987; 1996), and research exploring the health effects of neighborhood context to elaborate and test two sets of hypotheses. First, we extend the typical focus on the health consequences of neighborhood poverty to include a range of other structural characteristics of neighborhoods including the concentration of affluence, residential stability, and ethnic heterogeneity. Our focus on the role of affluence, in particular, builds on recent theory and research highlighting the potentially important role of middle and upper-middle class residents in anchoring community institutions and providing organizational and economic resources with which to promote a healthy environment (Cagney, Browning, and Wen 2002; Robert 1998). Wilson's theory of social 
isolation adds the additional insight that residential stability may interact with socioeconomic context in influencing the well-being of urban residents (Wilson 1987; 1996; Ross, Reynolds, and Geis 2000).

Second, we elaborate and test a number of hypotheses regarding the community-level mechanisms thought to mediate the effects of structural conditions at the neighborhood level. The mechanisms we consider include neighborhood level social support and sociability (Berkman 1995; Berkman, Glass, Brissette, and Seeman 2000; Berkman and Syme 1979; Hawe and Shiell 2000), normative transmission of health-compromising behavior (Fitzpatrick and Lagory 2000), and healthrelated collective efficacy (Browning and Cagney 2002; Sampson, Raudenbush, and Earls 1997). Though some studies have examined the impact of individual mechanisms, this research has either focused on relatively large units of aggregation (e.g., the state level [Kawachi, Kennedy, Lochner, and ProthrowStith 1997]) or has used person level operationalizations of processes specified to operate at the neighborhood level (Ross and Mirowsky 2001). In contrast, we consider multiple hypotheses regarding the neighborhood level mediators of socioeconomic structure effects on health simultaneously.

We investigate neighborhood effects on health using a multilevel statistical approach (Raudenbush and Bryk 2002; Snijders and Bosker 1999). Three data sources are employed: 1990 decennial census data, the 1994-95 Project on Human Development in Chicago Neighborhoods Community Survey (PHDCN-CS), and the 1991-2000 Metropolitan Community Information Center-Metro Survey (MCIC-MS) - a serial cross-section of Chicago adults. The combination of these data sets offers a unique opportunity to assess the contribution of multiple dimensions of neighborhood structure and social process to variations in the health of urban residents.

\section{THEORETICAL PERSPECTIVES}

\section{Neighborhood Socioeconomic Structure and Health}

The contribution of neighborhood structure to health has been the subject of extensive empirical investigation, but the theoretical basis for this association has received comparatively less attention. We draw on recent extensions of the longstanding tradition of theory and research on the role of "social disorganization" in the spread of urban social problems (Bursik 1988; Shaw \& McKay 1969; Sampson, Raudenbush, and Earls 1997). Though originally developed as an explanation for varying crime rates across urban neighborhoods, this body of theory identifies specific dimensions of neighborhood structure that may be relevant to the distribution of a wide range of phenomena, including poor health.

Social disorganization theory has a lengthy history in urban sociology. In Shaw and McKay's (1969) initial statements of the approach and subsequent elaborations (Kornhauser 1978), features of neighborhood structure-principally poverty, residential instability, and ethnic heterogeneity-were hypothesized to limit resources with which to support local institutions, diminish community attachments through high population turnover, and impede communication across diverse racial/ethnic groups. In turn, these conditions result in attenuated community-level social control of crime. In their empirical analyses, Shaw and McKay found that these structural factors continued to affect crime rates regardless of ethnic and racial population succession, suggesting that macro level processes operate independently of the characteristics of individuals who comprise disadvantaged neighborhoods. This insight remains critical to research on neighborhood effects today. For instance, deficits in the health of African-Americans and Latinos by comparison with whites observed at the individual level may actually be capturing inequality in the social environments these groups typically occupy.

These early efforts at describing the spatial organization of social problems have seen renewed interest over the last two decades. Research examining the contextual impact of economic conditions on health, for instance, has highlighted the potential relevance of social disorganization theory to health outcomes (Robert 1999). Indeed, the neighborhood level consequences hypothesized to follow from structural deficits in the disorganization approach-attenuated institutional strength, limited network interaction, diminished neighborhood attachment, and low levels of informal social control (Kasarda and Janowitz 1974; Kornhauser 1978; Sampson 
1997)_ can be seen as potentially important determinants of health as well as outcomes such as victimization. We describe this process in more detail in our discussion of the hypothesized mechanisms linking neighborhood structure with health. In particular, we emphasize the role of collective efficacy-or the combination of social cohesion and shared expectations for beneficial action on behalf of the community - as a critical intervening social process relevant to health outcomes (Sampson, Raudenbush, and Earls 1997).

An important insight of the collective efficacy extension of social disorganization theory concerns the potential significance of the presence of affluent residents for neighborhood social organization (Sampson, Morenoff, and Earls 1999; Sampson, Raudenbush, and Earls 1997). Consistent with this emphasis, research on health has increasingly emphasized the distribution of advantage as a critical dimension of community economic structure (Cagney, Browning, and Wen 2002; Robert 1998). Affluent residents may draw more and higher quality health services and reinforce the viability of local organizations and services that indirectly benefit health (e.g, parks and recreational services). Indeed, while findings regarding the negative effects of disadvantaged neighborhood SES on health have been reasonably consistent (Davey Smith, Hart, Watt, Hole, and Hawthome 1998; Diez-Roux, Nieto, Muntaner, Tyroler, Comstock, Shahar, Cooper, Watson, and Szklo 1997; Haan, Kaplan, and Camacho 1987; Humphreys and Carr-Hill 1991; Jones and Duncan 1995; Katz, Kling, and Liebman 2001; Krieger 1992; LeClere, Rogers, and Peters 1997; Leventhal and Brooks-Gunn 2001; Waitzman and Smith 1998; Yen and Kaplan 1999), some studies have found no effect of concentrated poverty or disadvantage after controlling for individual level SES (Ecob 1996; Sloggett and Joshi 1994). Moreover, studies that find an association between neighborhood SES and health have often employed measures that tap some combination of the prevalence of poverty and affluence (LeClere, Rogers, and Peters 1998; Ross and Mirowsky 2001).

Few studies have specifically examined the effects of the upper end of the neighborhood socioeconomic continuum on health. In an investigation of community SES effects on the health of older persons, Cagney, Browning, and Wen (2002) found that a measure of the proportion of households with incomes over $\$ 50,000$ was significantly associated with better health independent of demographic and health background while the prevalence of poverty was not a significant predictor of health. Robert (1999) found that a measure of the proportion of residents with incomes greater than $\$ 30,000$ had a direct positive effect on the health of individuals. Consequently, a focus on the prevalence of affluence as an important structural determinant of health is theoretically plausible and consistent with previous empirical findings.

Finally, Wilson's theory of social isolation $(1987 ; 1996)$ has called attention to the potential for structural features of communities to interact in their influence on individual wellbeing. Wilson's model emphasizes a two-stage dynamic process of neighborhood decline. First, the flight of middle class residents of inner city communities results in the declining viability of local institutions-including churches, schools, voluntary organizations, and the family - and corresponding deficits in the capacity of residents to maintain informal social controls. Second, as the regulatory capacity of the community diminishes, residents are increasingly exposed to problem behaviors. In turn, these (potentially healthcompromising) behavioral orientations may be transmitted by precept, further contributing to community decline. The structural context in which this process occurs most efficiently is one characterized by both widespread economic disadvantage and constrained mobility.

Contrary to the traditional social disorganization emphasis on the beneficial effects of residential stability, then, this approach views residentially stability as potentially exacerbating the effects of economic disadvantage. We extend investigation of the consequences of social isolation to consider the potential interaction between stability and both the prevalence of poverty and affluence. Consistent with the second stage of Wilson's model of neighborhood decline, stable poverty may encourage the dissemination of health-compromising subcultures (Fitzpatrick and LaGory 2000). Consistent with the first stage of Wilson's model, however, stable neighborhoods that lack affluent residents may experience long term declines in the institutional fabric (including, potentially, the quality and availability of health services) and informal social 
control capacity of the community, with consequences for health.

In sum, building on recent extensions to the social disorganization approach in the form of collective efficacy theory and Wilson's concept of social isolation, we focus on aspects of neighborhood socioeconomic structure beyond poverty that are theoretically relevant to individual health. These include concentrated affluence, residential stability, and ethnic heterogeneity. Acknowledging the unique conditions of extremely disadvantaged and socially isolated communities, we also consider the potential for community economic structure (both the concentration of poverty and affluence) to condition the impact of residential stability on health outcomes. A focus on structural characteristics of communities alone, however, leaves unanswered a critical question: what mechanisms link community structural characteristics with health outcomes?

\section{Mechanisms Linking Neighborhood Structure with Health}

Hypotheses regarding the impact of distinct dimensions of community structure require specification of the mechanisms by which individual health status is likely to be influenced. A focus on theories of social organization points largely to the intervening impact of the prevalence of social ties and collective efficacy, as we shall see. However, other plausible sociocultural mechanisms have been hypothesized to channel the impact of community SES-most notably, subcultural tolerance of health compromising behavior and anomie at the neighborhood level. Below, we consider hypotheses regarding the effects of social interaction and sociability, health-related subcultures, and collective efficacy in turn.

Informal Social Support, Sociability, and Health. The increasingly vast literature on the role of informal social supports in promoting health at the individual or egocentric network level has fostered interest in the effects of community level social network characteristics on health. Structurally disadvantaged neighborhoods may be less capable of sustaining viable social networks and may suffer from deficits in local social support and sociability (Berkman and Breslow 1983).

Berkman and colleagues (Berkman, Glass, Brissette, and Seeman 2000), for instance, sug- gest that networks of networks at the community level influence egocentric connectedness and health-enhancing processes such as social support (House 1981), positive influence, and sociability (Berkman, Glass, Brissette, and Seeman 2000; Rook 1990). Evidence of the positive effects of social support on health is powerful and consistent (Berkman and Syme 1979; House, Robbins, and Metzner 1982; Orth-Gomer and Johnson 1987), suggesting that the prevalence of social support activity and community social engagement at the neighborhood level may also be relevant for health outcomes.

Social Organization, Subcultural Transmission and Health. The subcultural perspective on health can be characterized with reference to the second stage of Wilson's theory of neighborhood decline. According to Wilson, the combination of poverty and immobility results in the social and spatial isolation of neighborhood residents from mainstream sources of influence. Modeling and transmission of problematic behavioral strategies ensue. Some of these behavioral orientations may be adaptive for survival (such as display of a "tough" or violent demeanor [Anderson 1990] ). However, cultural transmission of violent and other risky behavior (such as smoking, drinking, risky sexual activity, and poor diet) in these contexts may have serious consequences for health.

Applying Wilson's concept of social isolation explicitly to health outcomes, Fitzpatrick and LaGory (2000) suggest that disadvantaged communities with limited access to extra-local mainstream institutions may experience the emergence of "health-related subcultures." Two aspects of these subcultural orientations may have consequences for health: 1) tolerance for risky lifestyles and 2) anomie or detachment from conventional values. First, widespread community level tolerance of risk behavior, including smoking, drinking, drug use, and poor diet, may facilitate the spread of such behavior within disadvantaged contexts, with consequences for health.

Second, structural disadvantage, characterized by widespread poverty, lack of access to employment, and bleak economic prospects, may lead to anomic social conditions (Durkheim 1979; Sampson and Bartusch 1998) in which neighborhood residents question basic normative orientations (e.g., the value of abiding by the law and of employing 
conventional means such as education and hard work to achieve success). Since the benefits of adherence to basic cultural values are perceived not to accrue to residents of some disadvantaged neighborhoods, the force of value based prescriptions weakens in these contexts. Possible adaptations to these conditions include the emergence of largely shortterm, instrumental orientations toward goals marked by little concern for the future. As applied to health, this hypothesis would suggest that anomie-induced short-term, "here and now" orientations emphasizing satisfaction of immediate needs will tend to be associated with health-compromising behaviors. While an extensive literature has documented the role of individual level risk behaviors in promoting individual level health (Blair, Kohl, Paffenbarger, Clark, Cooper, and Gibbons 1989; Paffenbarger, Hyde, Wing, Lee, Jung, and Kampert 1993), few studies to date have attempted to assess the health effects of community-level tolerance of risk behavior and anomie.

Collective Efficacy and Health. A third perspective highlights the capacity for action on behalf of community goals as the critical intervening mechanism linking community structure with health. Sampson and colleagues (Sampson, Raudenbush, and Earls 1997) have encapsulated this process in the concept of collective efficacy, which emphasizes mutual trust and solidarity (social cohesion), and shared expectations for pro-social action (informal social control) in theorizing the impact of neighborhood social organization on local resident's well-being. While acknowledging that local social ties may contribute to these dimensions of community social organization, the collective efficacy approach must be seen as distinct from the neighborhood social support and sociability perspective to the extent that it emphasizes the sense of attachment to community and the perceived willingness of community residents to intervene on each others' behalf regardless of preexisting social ties. ${ }^{1}$

The pathways through which neighborhood collective efficacy may influence health include the social control of health-risk behavior, access to services and amenities, the management of neighborhood physical hazards, and psychosocial processes (Browning and Cagney 2002; Kawachi and Berkman 2000). First, Sampson, et al. (1997) have demonstrat- ed the powerful effects of collective efficacy on rates of violence-suggesting that health may be influenced by high levels of collective efficacy through limiting the health damaging consequences of violent victimization. Other forms of problem behavior including illicit substance use, alcohol abuse, child and elder neglect/abuse, and reckless behavior may also be held in check by high levels of collective social control (Sampson 1997). Second, collective efficacy may enhance the capacity of communities to attract and maintain high quality health services and amenities such as community health clinics and safe recreational space. Third, collective efficacy may aid in correcting or avoiding the accumulation of neighborhood physical hazards such as decaying infrastructure and housing stock. Communities with the capacity to solicit and secure external resources to correct potentially risky conditions and monitor vulnerable residents (e.g., the elderly) are likely to enhance health. Finally, the effect of widespread trust and neighborhood attachment on factors such as fear and self-respect may improve the health and well-being of residents-even if they do not benefit from direct network support (Kawachi and Berkman 2000).

The empirical investigation to follow considers the impact of affluence, residential stability, and ethnic heterogeneity on health, in addition to poverty, in an effort to extend the typically more narrow focus on the latter in analyses of neighborhood effects on health. We then consider the potential for mediating or unique effects of the three intervening social processes considered-social support and sociability, subcultural tolerance for risk behavior and anomie, and collective efficacy. We stress that these social processes need not be considered mutually exclusive or fundamentally contradictory. Nevertheless, by attempting to adjudicate between these mechanisms, we take seriously their distinct emphases and, in so doing, hopefully illuminate the specific community level social conditions that contribute to individual health.

\section{DATA AND MEASURES}

We use three data sources to explore the association between neighborhood context and health - the 1990 Decennial Census, the 1994-95 Project on Human Development in 
Chicago Neighborhoods-Community Survey (PHDCN-CS), and the 1991-2000 Metropolitan Chicago Information Center Metro Survey (MCIC-MS). Measures of neighborhood structural disadvantage are taken from census data. Measures of neighborhood social processes are constructed from the PHDCN-CS, a probability sample of 8,782 residents of Chicago focusing on respondent assessments of the communities in which they live. The PHDCN-CS combined 865 census tracts into 343 "neighborhood clusters" (NCs) maintaining relative population homogeneity with respect to racial/ethnic, socioeconomic, housing, and family structure characteristics (NCs average roughly 8,000 people). ${ }^{2}$ The three-stage sampling strategy selected city blocks within NCs, dwelling units within blocks, and respondents (one adult, age 18 or over, per household) within dwelling units. The PHDCN-CS sampling strategy was intended to capture a within-NC sample sufficient to estimate neighborhood characteristics based on aggregated individual level data - ensuring the reliability of neighborhood level measures of social processes. $^{3}$

The dependent variable and individual level predictors are drawn from the MCIC-MS. The MCIC-MS is a serial cross-section of adults ages 18 and older residing in the six county metropolitan Chicago area (averaging around 3,000 respondents per wave, roughly 1,000 of which fall within the City of Chicago) focusing on a wide variety of individual level measures of well-being, including self-rated health. ${ }^{4}$ The MCIC-MS sample captured 339 of the 343 PHDCN NCs $(\mathrm{N}=3,272)$. Though the data are not longitudinal, rendering the determination of causation problematic, they do include a number of individual level health background controls (detailed below).

\section{Dependent Measure}

Our dependent variable is a measure of selfrated health, considered a robust measure of general health status (Goldstein, Siegel, and Boyer 1984; Wilson and Kaplan 1995). The validity of self-rated health as a predictor of mortality (Benyamini and Idler 1999; Idler and Angel 1990; Idler and Benyamini 1997; Kaplan, Barell, and Lusky 1988), morbidity (Ferraro, Farmer, and Wybraniec 1997), subsequent disability (Idler and Kasl 1995; Kaplan,
Strawbridge, Camacho, and Cohen 1993) and health care utilization (Andersen 1987; Malmstrom, Sundquist, and Johansson 1999) has been widely documented. Furthermore, self-assessed health is a stronger predictor of mortality than is physician-assessed health (Mossey \& Shapiro, 1982). Although validity assessments of the self-rated health measure across dimensions such as gender, race and ethnicity still merit further exploration (Idler and Benyamini 1997), initial investigations indicate that its predictive capacity is comparable for Latinos, African Americans and Whites (Finch, Hummer, Reindel, and Vega 2002; Gibson 1991; Johnson and Wolinsky 1994). ${ }^{5}$

The MCIC-MS asks "In general, would you say your health is: excellent, good, fair or poor?" Consistent with a number of previous analyses (Idler and Benyamini 1997; Benyamini and Idler 1999), we treat self-rated health as a dichotomy, collapsing reports of "fair" or "poor" health in order to capture respondents at the low end of the health distribution (Wolinsky and Tierney 1998). Table 1 reports the proportion of MCIC-MS respondents reporting each level of health; $22.3 \%$ reported being in fair or poor health.

\section{Independent Measures}

We constructed measures of neighborhood level social composition from the 1990 decennial census. In operationalizing economic structure, we chose to focus on the prevalence of poor and middle/upper middle class residents as defined by income. For the purposes of a comparative analysis, this approach allows for an assessment of concentrations in the upper and lower tails of a single dimension. ${ }^{6}$ Poverty was operationalized as the proportion of neighborhood residents with incomes below the poverty line. Affluence captured the percentage of households with incomes over $\$ 50,000$. A residential stability scale was constructed based on scores from a factor analysis of measures of housing tenure (percent living in the same house since at least 1985) and the percent of housing occupied by owners (factor loadings exceeded .75). ${ }^{7}$ Tapping ethnic heterogeneity in the context of Chicago, a second factor-immigrant concentration - was marked by high factor loadings for percent Latino (.88) and percent foreign born (.70). ${ }^{8}$

Collective efficacy was operationalized 
TABLE 1. Descriptive Statistics for Variables in the Analysis

\begin{tabular}{|c|c|c|}
\hline Variables & Mean & St dev. \\
\hline \multicolumn{3}{|l|}{ Self-rated health } \\
\hline Excellent & .335 & \\
\hline Good & .443 & \\
\hline Fair & .175 & \\
\hline Poor & .048 & \\
\hline \multicolumn{3}{|l|}{ Demographic background } \\
\hline Female & .590 & \\
\hline Age & 42.74 & 15.99 \\
\hline \multicolumn{3}{|l|}{ Race } \\
\hline White/other & .459 & \\
\hline Black & .349 & \\
\hline Latino & .192 & \\
\hline \multicolumn{3}{|l|}{ Income } \\
\hline$<\$ 10,000$ & .091 & \\
\hline$\$ 10-000-\$ 15,000$ & .073 & \\
\hline$\$ 15,000-\$ 20,000$ & .069 & \\
\hline$\$ 20,000-\$ 25,000$ & .068 & \\
\hline$\$ 30,000-\$ 40,000$ & .091 & \\
\hline$\$ 40,000-\$ 50,000$ & .147 & \\
\hline$\$ 50,000-\$ 60,000$ & .126 & \\
\hline$\$ 60,000-\$ 70,000$ & .151 & \\
\hline$\$ 70,000-\$ 90,000$ & .101 & \\
\hline$>\$ 90,000$ & .082 & \\
\hline \multicolumn{3}{|l|}{ Education } \\
\hline 4 th grade or less & .014 & \\
\hline 5 th to 8 th grade & .053 & \\
\hline 9th to 12 th grade, no diploma & .106 & \\
\hline High school graduate & .165 & \\
\hline Trade or vaocational school & .077 & \\
\hline Some college & .263 & \\
\hline College graduate & .163 & \\
\hline Some graduate study & .033 & \\
\hline Graduate degree & .125 & \\
\hline Married & .391 & \\
\hline Years resident in the neigh. & 11.52 & \\
\hline Home ownership & .430 & \\
\hline Foreign born & .177 & \\
\hline \multicolumn{3}{|l|}{ Health background } \\
\hline \multicolumn{3}{|l|}{ Exercise per week } \\
\hline Never & .336 & \\
\hline Once or twice & .241 & \\
\hline Two to three times & .186 & \\
\hline Four times or more & .237 & \\
\hline Smoking & .285 & \\
\hline Weight problem & .196 & \\
\hline \multicolumn{3}{|l|}{ Insurance } \\
\hline Private insurance & .671 & \\
\hline Medicaid & .083 & \\
\hline Medicare & .077 & \\
\hline No insurance & .169 & \\
\hline
\end{tabular}

Note: $\mathrm{N}=3272$ through combining measures of social cohesion and informal social control. Social cohesion was captured using a cluster of conceptually related items from the PHDCN-CS measuring the respondent's level of agreement (on a five-point scale) with the following statements: (1) "people around here are willing to help their neighbors," (2) " this is a close-knit neighborhood", (3) "people in this neighborhood can be trusted," and (4) "people in this neighborhood generally don't get along with each other" (reverse coded). Health-related informal social control was tapped through items measuring the respondent's level of agreement with the following statements: (1) "If I were sick I could count on my neighbors to shop for groceries for me" and (2) "You can count on adults in this neighborhood to watch out that children are safe and don't get in trouble." An additional informal control item asked respondents how likely it is that neighbors would intervene if "there was a fight in front of your house and someone was being beaten or threatened." The informal control items tap expectations for beneficial health-related action as well as neighborhood supervision of potentially hazardous conditions or violent situations. ${ }^{9}$ The seven items were combined to form a single scale of health-related collective efficacy. The reliability of the collective efficacy scale is $.73 .{ }^{10}$

The local social support and sociability scale encompassed a number of items measuring the extent of the respondent's neighborhood-based friendship networks (how many friends the respondent has in the neighborhood and the ratio of friends inside and outside the neighborhood), as well as the frequency of parties, visits, advice giving, and favor exchange among neighbors. The latter four items were constructed from questions asking respondents (1) "how often do you and people in this neighborhood have parties or other get-togethers where other people in the neighborhood are invited?," (2) "how often do you and other people in this neighborhood visit in each other's homes or on the street?," (3) "how often do you and other people in the neighborhood ask each other advice about personal things such as child rearing or job openings?," and (4) "how often do you and people in your neighborhood do favors for each other?"11 These items are intended to tap aspects of community level instrumental, informational, and appraisal support as well as the level of sociability charac- 
terizing the neighborhood (House, Landis, and Umberson 1988). The reliability of the social support and sociability scale is .60.

Subcultural orientations were captured with two scales - a measure of tolerance for youthful deviance and problem behaviors and a measure of legal cynicism. Eight items were used to measure tolerance for risk behavior. Respondents were asked their opinions regarding how wrong it is for nineteen-year-olds to smoke cigarettes, use marijuana, drink alcohol, and get into fistfights. Though questions were not asked about tolerance for such behavior by adults at any age, the items nevertheless capture an underlying dimension of permissiveness that is likely associated with neighborhood level sanctioning of comparable adult behavior. The reliability of the deviance tolerance scale is .61. Anomie was measured using the respondent's level of agreement with the following statements: (1) "laws were made to be broken," (2) "it's okay to do anything you want as long as you don't hurt anyone," (3) "to make money, there are no right and wrong ways anymore, only easy ways and hard ways," and (4) "fighting between friends or within families is nobody else's business." This scale is intended to capture "anomie" (detachment from conventional norms) and fatalistic orientations that may increase the likelihood of health-risk behavior or failure to seek medical attention or advice (Sampson and Bartusch 1998). The reliability of the anomie scale is 63 .

Neighborhood disorder was included as a control in models examining links between structural disadvantage and health in order to tap social conditions hypothesized to cue the breakdown of social order and the potential for corresponding increases in stress levels (Ross and Mirowsky 2001). Social and physical disorder could be confounded with the other mechanisms examined below (Sampson and Raudenbush 1999). The level of disorder in the neighborhood was measured with four items inquiring into respondent assessments of the prevalence of public drinking, abandoned buildings, litter and trash, and graffiti. The reliability of the disorder scale is .88 . The aggregation procedure for multi-item neighborhood survey-based measures is described in more detail below (Analytic Strategy).

Finally, we include controls for prior neighborhood health and population size. Prior neighborhood health was included in order to ensure that any effects of social organization variables (e.g., social support and sociability) were not simply capturing the effects of a consistently poor neighborhood on network withdrawal and community engagement (i.e., the potential endogeneity of social organization). Prior neighborhood health was estimated from the 1992-1994 waves of the MCIC by aggregating individual responses to the self-rated health item to the neighborhood cluster level (see Appendix 1 for correlations among neighborhood level variables).

Individual level variables are taken from the 1995,' 97 , and '99 waves of the MCIC-MS. Of the waves of the MCIC-MS available from 1995 through 2000, only '95, '97, and '99 include the necessary individual level controls for health background. We include a variable for interview year to capture any time trends in the dependent variable. Table 1 reports descriptive statistics on the key demographic background and health related items used in the analyses. Included are measures of gender, race/ethnicity (Black, Latino versus White/other), age, income, education level, marital status (married versus single or cohabiting), number of years resident in the respondent's current neighborhood, homeownership, and whether the respondent is foreign born. Health measures include insurance coverage (Medicaid, Medicare, or no insurance coverage versus private insurer), dummy variables measuring a doctor-indicated weight problem and current smoking, and a measure of the frequency of exercise per week in four categories.

\section{ANALYTIC STRATEGY}

We use Hierarchical Linear and Non-linear Modeling techniques to account for the complex error structure of multilevel models of health outcomes. The analyses reported in tables 2 and 3 are two-level hierarchical (random intercept) logit models of the dichotomized self-rated health measure. ${ }^{12} \mathrm{We}$ report coefficients (in log form) in the table but refer to percentage changes in odds in the text (exponentiated coefficients).

In order to correct independent neighborhood level measures of collective efficacy, network density, subcultural orientations, disorder, and prior neighborhood health for missing data and social composition, we use empirical bayes residuals from multilevel models of each 
outcome (Bryk and Raudenbush 1992; Snijders and Bosker 1999). As an illustrative example, we describe the three level item response model used to construct our measure of neighborhood collective efficacy (Sampson, Raudenbush, and Earls 1997). At level one (within individuals) - the seven items comprising the collective efficacy scale are modeled as follows:

$$
\mathrm{Y}_{i j k}=\pi_{j k}+\sum_{p=1}^{6} \alpha_{p} D_{p i j k}+e_{i j k},
$$

where $Y_{i j k}$ is the response to item $i$ of person $j$ in neighborhood $k, \pi_{j k}$ is the intercept, $D_{p i j k}$ is a dummy variable taking on a value of 1 if response $i$ is to item $p$ in the 6 item collective efficacy scale and 0 otherwise, and $e_{i j k}$ are errors of measurement assumed to be independent. Respondents who provide answers to any of the scale items contribute information to the analysis, though HLM weights cases with full information more heavily.

At level two (between individuals), respondent-specific latent perceptions of collective efficacy are adjusted for individual level characteristics as follows:

$$
\pi_{j k}=\beta_{0 k}+\sum_{q=1}^{13} \beta_{q} X_{q j k}+r_{j k}, \quad r_{i j} \sim N\left(0, \sigma^{2}\right)
$$

where $\beta_{0 k}$ is the intercept, $X_{q j k}$ is the value of person-level predictor $q$ for individual $j$ in neighborhood $k, \beta_{q}$ is the effect of $q$ on individual $j$ 's expected score, and $r_{j k}$ is an independently, normally distributed error term with variance $\sigma^{2}$. The models adjust for thirteen covariates including gender, age, race/ethnicity (black, Latino vs. white), education, employment status (employed vs. not employed), marital status (never married, other vs. married), homeownership, years resident in the neighborhood, and number of moves in the last five years. The level two model also includes a measure of the respondent's social embeddedness based on responses to the social support and sociability items described above. This control ensures that the neighborhood level measure of collective efficacy is not confounded with individual level social support and sociability. Finally, adjusted neighborhood intercepts are modeled as follows:

$$
\beta_{0 k}=\gamma_{00}+u_{0 k}, \quad u_{0 k} \sim \mathrm{N}\left(0, \tau_{00}\right)
$$

where $\gamma_{00}$ is the grand mean and $u_{0 k}$ is a level three random effect. The neighborhood level collective efficacy score ultimately included as an independent variable in multilevel logit models of the self-rated health outcome is the standardized empirical bayes residual from the level three model. Empirical bayes estimates take into account differences in the reliability with which $\beta_{0 k}$ has been estimated (Bryk and Raudenbush 1992).

\section{RESULTS}

We begin by investigating the relationship between health and antecedent structural variables in multivariate context. Table 2 reports the results of a series of hierarchical logit models of self-rated health on individual and neighborhood level characteristics. The intraclass correlation from the unconditional model indicates that roughly $6 \%$ of the variance in self-rated fair or poor health (hereafter "poor" health) lies at the neighborhood level (apparently small intra-class correlations can veil relatively large effects of individual neighborhood coefficients [Duncan and Raudenbush 1999])..$^{13}$

Model 1 predicts self-rated health based on demographic background factors. Consistent with expectations and previous research, age and African-American race/ethnicity increase the likelihood of poor self-rated health. Women and foreign-born respondents also report poorer health. Income, education, and interview year are strongly negatively associated with poor health. The association between interview year and health indicates that health improved over the five years covered by the 1995, '97, and '99 MCIC samples. Model 2 adds controls for health behavior and insurance coverage. Weight problems and Medicare, Medicaid, or no insurance coverage (by comparison with private insurance coverage) are all positively associated with poor health while exercise benefits health. Though reduced in Model 2, the effect of AfricanAmerican race/ethnicity remains after controlling for health background, indicating that the odds of reporting poor health are $47 \%$ higher than the odds for Whites. ${ }^{14}$

Model 3 includes only neighborhood structural characteristics in order to examine the effect of these variables without individual level controls. Controlling only for interview year, poverty, residential stability, and immigrant concentration are all positively associat- 
TABLE 2. Hierarchical Logit Models of Self-Rated Fair or Poor Health on Individual Background, Health Behavior, Insurance Coverage, and Neighborhood Characteristics

\begin{tabular}{|c|c|c|c|c|c|c|}
\hline \multirow{2}{*}{$\begin{array}{l}\text { Independent } \\
\text { Variables }\end{array}$} & \multicolumn{6}{|c|}{ Fair or Poor Health } \\
\hline & 1 & 2 & 3 & 4 & 5 & 6 \\
\hline \multicolumn{7}{|l|}{ Individual level } \\
\hline \multirow[t]{2}{*}{ Female } & $.216^{*}$ & .146 & - & .145 & .144 & .147 \\
\hline & $(.097)$ & $(.100)$ & & (.099) & $(.101)$ & $(.103)$ \\
\hline \multirow[t]{2}{*}{ Age } & $.028 * *$ & $.025^{* *}$ & - & $.025 * *$ & $.026 * *$ & $.026 * *$ \\
\hline & $(.004)$ & $(.005)$ & & $(.005)$ & $(.005)$ & $(.005)$ \\
\hline \multirow[t]{2}{*}{ Black } & $.468 * *$ & $.384 * *$ & - & $.425 * *$ & .238 & .250 \\
\hline & $(.104)$ & $(.108)$ & & $(.134)$ & $(.142)$ & $(.142)$ \\
\hline \multirow[t]{2}{*}{ Latino } & .172 & .136 & - & .140 & .086 & .072 \\
\hline & $(.153)$ & $(.160)$ & enta to & $(.159)$ & $(.157)$ & $(.158)$ \\
\hline \multirow[t]{2}{*}{ Income } & $-.076^{* *}$ & $-.051 *$ & -1 & $-.054 *$ & $-.046^{*}$ & $-.047 *$ \\
\hline & $(.021)$ & $(.022)$ & & $(.021)$ & $(.022)$ & $(.022)$ \\
\hline \multirow[t]{2}{*}{ Education } & $-.245^{* *}$ & $-.216^{* * *}$ & 111 & $-.215 * *$ & $-.200^{*}$ & $-.199 * *$ \\
\hline & $(.030) P$ & $(.030)$ & & $(.032)$ & $(.031)$ & $(.032)$ \\
\hline \multirow[t]{2}{*}{ Married } & .150 & .145 & - & .132 & .137 & .140 \\
\hline & $(.104)$ & $(.105)$ & & $(.105)$ & $(.105)$ & $(.107)$ \\
\hline \multirow[t]{2}{*}{ Years in the neighborhood } & -.003 & -.003 & - & -.004 & -.005 & -.005 \\
\hline & $(.008)$ & $(.008)$ & & $(.008)$ & $(.008)$ & $(.008)$ \\
\hline \multirow[t]{2}{*}{ Home ownership } & -.118 & -.058 & - & -.147 & -.133 & -.142 \\
\hline & $(.115)$ & $(.117)$ & & $(.123)$ & $(.124)$ & $(.124)$ \\
\hline \multirow[t]{2}{*}{ Foreign born } & $.369 * *$ & $.467 * *$ & - & $.482 * *$ & $.493 * *$ & $.497 * *$ \\
\hline & $(.132)$ & $(.136)$ & & $(.136)$ & $(.134)$ & $(.136)$ \\
\hline \multirow[t]{2}{*}{ Interview year } & $-.169 * *$ & $-.187 * *$ & $-.189 * *$ & $-.188 * *$ & $-.188 * *$ & $-.189 * *$ \\
\hline & $(.032)$ & $(.003)$ & $(.029)$ & $(.033)$ & $(.033)$ & $(.034)$ \\
\hline \multirow[t]{2}{*}{ Exercise frequency per week } & - & $-.095^{*}$ & - & $-.095 *$ & $-.096^{*}$ & $-.098 *$ \\
\hline & & $(.039)$ & & $(.039)$ & $(.039)$ & $(.040)$ \\
\hline \multirow[t]{2}{*}{ Smoking } & - & .197 & - & .212 & .192 & .197 \\
\hline & & $(.106)$ & & $(.106)$ & $(.107)$ & $(.108)$ \\
\hline \multirow[t]{2}{*}{ Weight problem } & - & $.756^{* *}$ & - & $.752 * *$ & $.740 * *$ & $.746^{* *}$ \\
\hline & & $(.107)$ & & $(.106)$ & $(.107)$ & $(.107)$ \\
\hline \multirow[t]{2}{*}{ Medicare } & - & $.558 * *$ & - & $.572 * *$ & $.549 * *$ & $.554 * *$ \\
\hline & & $(.168)$ & & $(.170)$ & $(.170)$ & $(.171)$ \\
\hline \multirow[t]{2}{*}{ Medicaid } & - & $.470 * *$ & - & $.476 * *$ & $.463 * *$ & $.461 * *$ \\
\hline & & $(.165)$ & & $(.166)$ & $(.169)$ & $(.170)$ \\
\hline \multirow[t]{2}{*}{ No insurance } & - & $.442 * *$ & - & $.444 * *$ & $.440 * *$ & $.444 * *$ \\
\hline & & $(.135)$ & & $(.132)$ & $(.134)$ & $(.135)$ \\
\hline Neighborhood level & & & & & & \\
\hline Total population & - & - & .018 & .022 & $.039 * *$ & $.032 *$ \\
\hline & & & $(.013)$ & $(.014)$ & $(.014)$ & $(.014)$ \\
\hline Residential stability & - & - & $.288 * *$ & $.107 *$ & $.183^{* *}$ & $.249 * *$ \\
\hline & & & $(.046)$ & $(.052)$ & $(.054)$ & $(.062)$ \\
\hline Immigrant concentration & 一 & & $.139 *$ & .014 & -.011 & .007 \\
\hline & & & & $(.079)$ & $(.079)$ & $(.077)$ \\
\hline Poverty & - & & & -.003 & - & - \\
\hline Affluence & - & & & - & $-.014^{*}$ & $-.014^{*}$ \\
\hline Stability*Affluence & - & - & - & - & - & $-.010^{*}$ \\
\hline & & & & & & $(.004)$ \\
\hline Intercept & $-1.513 * *$ & $-1.557 * *$ & $-1.243 * *$ & $-1.576^{* *}$ & $-1.549 * *$ & $-1.556 * *$ \\
\hline & $(.052)$ & $(.054)$ & $(.048)$ & $(.059)$ & $(.059)$ & $(.057)$ \\
\hline Intercept variance component & .031 & .057 & $.099 *$ & .039 & .050 & .026 \\
\hline
\end{tabular}

$* p<.05 ; * * p<.01$ (two-tailed tests). Standard errors in parentheses.

Note: Neighborhood $\mathrm{N}=339$; Individual $\mathrm{N}=3,272$.

ed with poor health. While the effects of poverty and immigrant concentration are consistent with the basic social disorganization perspective, the negative effect of residential stability is opposite of the expected positive effect.
Model 4 includes the three structural factors as well as demographic and health background characteristics. In contrast to a number of recent studies (Robert 1999), model 2 indicates that the effect of poverty on health in 
model 1 is due to the social composition of Chicago neighborhoods. ${ }^{15}$ That is, according to these data, neighborhood poverty exerts no independent effect on self-rated health when individual level characteristics are controlled. Residential stability, on the other hand, remains a significant negative predictor of health after individual controls have been included. Individual level covariates remain largely unchanged in Model 4, though the effect of individual level African-American race/ethnicity increases somewhat from Model 2.

Model 5 replaces poverty with a measure of the prevalence of affluence at the neighborhood level. The coefficient for affluence is significant and negative, indicating that increasing neighborhood affluence is health enhancing, independent of individual demographic and health background. Including affluence also results in a significant positive effect of population size on poor health and increases the magnitude of the residential stability effect. Notably, inclusion of neighborhood affluence reduces the magnitude of the coefficient for African-American race (by comparison with Model 4) by $44 \%$ and renders it insignificant at the conventional level.

Finally, the positive effect of residential stability on poor health suggests that stable neighborhoods are not health-protective, as social disorganization theory would hypothesize.
Model 6 tests Wilson's expectation that neighborhood economic structure (represented here by the significant effect of affluence ${ }^{16}$ ) conditions the effect of residential stability on health. Indeed, the interaction between affluence and stability is significant, indicating that as affluence increases, the positive effect of stability on poor health declines. Alternatively, as stability increases, the effect of affluence on poor health is increasingly negative. ${ }^{17}$

The conditional impact of residential stability at varying levels of neighborhood affluence is presented in Figure 1. The predicted probability of fair/poor health is plotted from -1.5 (low) to 1.5 (high) standard deviations on the residential stability scale for three levels of community affluence (corresponding to the mean and 1.5 standard deviations above and below the mean). Consistent with Wilson's interactive model, high levels of residential stability are positively associated with poor health at low levels of community affluence (2\%): The predicted probability of poor health increases significantly from .13 to .22 with a movement from 1.5 standard deviations below the mean on the residential stability scale to 1.5 standard deviations above the mean. By contrast, the significant positive effect of residential stability on poor health declines in communities with $18 \%$ affluent residents and becomes negative (though nonsignificant $[p>$

FIGURE 1. Probability of Fair/Poor Health by Neighborhood Residential Stability and Affluence Level

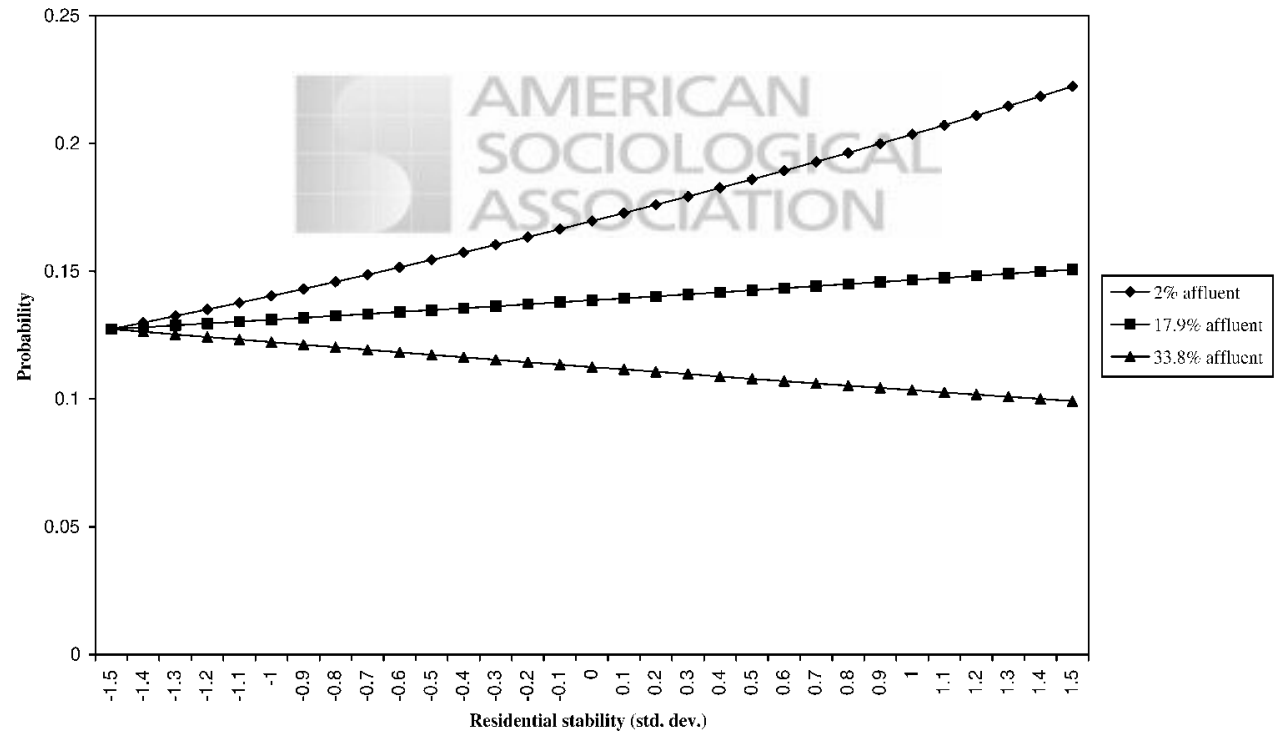


$.05]$ ) in communities with $34 \%$ affluent residents.

Thus, we find that neighborhood affluence is a more powerful predictor of self-rated health than poverty, but that its effect is conditioned by residential stability. Moreover, controlling for neighborhood affluence substantially diminishes the magnitude of the residual association between African-American race/ethnicity and self-rated health.

We next consider the role of intervening social process mechanisms in explaining the effects of structural characteristics on health. Table 3 reports the results of tests of the social organizational and cultural factors hypothesized to mediate neighborhood structural effects. Models 1 through 3 add measures of neighborhood social support and sociability, risk behavior tolerance and anomie, and collective efficacy in sequence. In addition to measures of neighborhood structure, controls for neighborhood disorder, population size, and prior neighborhood health are also included. ${ }^{18}$ As is clear, none of the intervening social process measures is significantly associated with health, with the sole exception of collective efficacy. Model 3 indicates that collective efficacy is negatively, and nontrivially associated with poor self-rated health. A two standard deviation increase on the collective efficacy scale results in a $27 \%$ reduction in the odds of reporting poor self-rated health. The introduction of the collective efficacy measure, however, results in negligible changes in the coefficients for neighborhood structural characteristics, suggesting that the effects of affluence and residential stability do not work principally through collective efficacy.

Finally, model 4 removes health background and insurance coverage from the individual level model while retaining the full battery of neighborhood effects. This strategy allows for an assessment of the possible extent to which neighborhood effects work through health behaviors to affect health outcomes. Model 4 offers little evidence that neighborhood effects are influencing self-rated health through health behaviors, with the possible exception of the coefficient for anomie. The effect of anomie achieves marginal significance $(p<.10)$ in Model 4, suggesting that health behaviors may partially mediate this effect. In sum, the analyses presented in Tables 2 and 3 offer evidence that neighborhood affluence, stability, and collective efficacy contribute, uniquely, to indi- vidual health, above and beyond individual demographic and health background.

\section{DISCUSSION}

Considerable research interest in the impact of neighborhood characteristics on health outcomes has generated a number of empirical efforts to assess these effects. This research has largely focused on the effects of prevalent neighborhood economic deprivation, however, to the exclusion of other potentially relevant structural characteristics. Moreover, to date, research on neighborhoods and health has not assessed the social mechanisms hypothesized to channel the impact of neighborhood structure on health outcomes. We extend existing research on the community context of health by examining multiple dimensions of neighborhood structure-including concentrated affluence, residential stability, and ethnic heterogeneity - in addition to poverty and examine a number of social processes hypothesized to be relevant in linking neighborhood structure with health. The latter include local social support and sociability, the emergence of subcultures of tolerance for deviant risk behavior and anomie, and collective efficacy. Research to date has not examined these distinct mechanisms simultaneously in order to isolate the community level social factors that are relevant for health.

Our analyses brought several data resources together in order to investigate neighborhood effects on self-rated health. Neighborhood level indicators of structural disadvantage from the 1990 census were combined with high quality indicators of social and cultural processes derived from the PHDCN-CS. These measures were merged with individual level data and a measure of prior neighborhood health taken from the MCIC-MS.

Our findings address a number of issues relevant to the discussion surrounding community effects on health. First, our analyses indicate that the effect of concentrated poverty of health is due to the social composition of poor neighborhoods. In the context of a model excluding individual background factors, a measure of neighborhood poverty was highly significant and positively associated with poor self-rated health. Yet, when we controlled for individual level characteristics, the impact of poverty on health was rendered insignificant. 
TABLE 3. Hierarchical Logit Models of Self-Rated Fair or Poor Health on Individual Background, Health Behavior, Insurance Coverage, and Neighborhood Characteristics

\begin{tabular}{|c|c|c|c|c|}
\hline \multirow{2}{*}{$\begin{array}{l}\text { Independent } \\
\text { Variables }\end{array}$} & \multicolumn{4}{|c|}{ Fair or Poor Health } \\
\hline & 1 & 2 & 3 & 4 \\
\hline \multicolumn{5}{|l|}{$\overline{\text { Individual level }}$} \\
\hline \multirow[t]{2}{*}{ Female } & .142 & .143 & .143 & $.209 *$ \\
\hline & $(.101)$ & $(.100)$ & $(.101)$ & $(.098)$ \\
\hline \multirow[t]{2}{*}{ Age } & $.026 * *$ & $.026 * *$ & $.026^{* *}$ & $.030 * *$ \\
\hline & $(.005)$ & $(.005)$ & $(.005)$ & $(.005)$ \\
\hline \multirow[t]{2}{*}{ Black } & .261 & .256 & .281 & $.382 * *$ \\
\hline & $(.146)$ & $(.147)$ & $(.145)$ & $(.137)$ \\
\hline \multirow[t]{2}{*}{ Latino } & .070 & .064 & .057 & .117 \\
\hline & $(.165)$ & $(.158)$ & $(.164)$ & $(.150)$ \\
\hline \multirow[t]{2}{*}{ Income } & $-.046^{*}$ & $-.046^{*}$ & $-.046^{*}$ & $-.069^{*}$ \\
\hline & $(.022)$ & $(.021)$ & $(.022)$ & $(.021)$ \\
\hline \multirow[t]{2}{*}{ Education } & $-.199 * *$ & $-.197 * *$ & $-.199 * *$ & $-.231 * *$ \\
\hline & $(.032)$ & $(.031)$ & $(.032)$ & $(.030)$ \\
\hline \multirow[t]{2}{*}{ Married } & .154 & .156 & .159 & .123 \\
\hline & $(.106)$ & (.105) & $(.106)$ & $(.104)$ \\
\hline \multirow[t]{2}{*}{ Years in the neighborhood } & -.005 & -.005 & -.005 & -.005 \\
\hline & $(.008)$ & $(.007)$ & $(.008)$ & $(.008)$ \\
\hline \multirow[t]{2}{*}{ Own home } & -.148 & -.144 & -.152 & -.199 \\
\hline & $(.123)$ & $(.121)$ & $(.122)$ & $(.120)$ \\
\hline \multirow{2}{*}{ Foreign born } & $.511 * *$ & $.509 * *$ & $.512 * *$ & $.394 * *$ \\
\hline & $(.140)$ & $(.136)$ & $(.138)$ & $(.131)$ \\
\hline \multirow[t]{2}{*}{ Interview year } & $-.191 * *$ & $-.191 * *$ & $-.187 * *$ & $-.149 * *$ \\
\hline & $(.033)$ & $(.033)$ & $(.033)$ & $(.028)$ \\
\hline \multirow[t]{2}{*}{ Exercise frequency } & -.098 & -.095 & $-.097 *$ & - \\
\hline & $(.039)$ & $(.039)$ & $(.040)$ & \\
\hline Smoking & .201 & .201 & .203 & - \\
\hline & $(.106)$ & $(.105)$ & $(.107)$ & \\
\hline Weight problem & $.746^{* *}$ & $.743 * *$ & $.736^{* *}$ & - \\
\hline & $(.107)$ & $(.107)$ & $(.106)$ & \\
\hline Medicare & $.562 * *$ & $.561 * *$ & $.561 * *$ & - \\
\hline & $(.173)$ & $(.171)$ & $(.175)$ & \\
\hline Medicaid & $.457 * *$ & $.449 * *$ & $.455^{* *}$ & - \\
\hline & $(.166)$ & $(.168)$ & $(.167)$ & \\
\hline No insurance & $.439 * *$ & $.448 * *$ & $.440 * *$ & - \\
\hline & $(.133)$ & $(.130)$ & $(.132)$ & \\
\hline Neighborhood level & & & & \\
\hline Total population & $.033^{*}$ & $.032 *$ & $.030 *$ & $.033^{*}$ \\
\hline & $(.014)$ & $(.014)$ & $(.014)$ & $(.014)$ \\
\hline Residential stability & $.250 * *$ & $.236 * *$ & $.244 * *$ & $.234 * *$ \\
\hline & $(.061)$ & $(.060)$ & $(.061)$ & $(.060)$ \\
\hline Immigrant concentration & .007 & -.008 & -.017 & .036 \\
\hline & $(.078)$ & $(.081)$ & $(.080)$ & $(.067)$ \\
\hline Affluence & $-.016^{*}$ & $-.015^{*}$ & $-.015^{*}$ & $-.019 * *$ \\
\hline & $(.007)$ & $(.007)$ & $(.006)$ & $(.006)$ \\
\hline Stability*Affluence & $-.010^{* *}$ & $-.010 * *$ & $-.010 * *$ & $-.008^{*}$ \\
\hline & $(.004)$ & $(.007)$ & $(.004)$ & $(.004)$ \\
\hline Prior neighborhood health & .029 & A.020 & .028 & -.005 \\
\hline & $(.046)$ & $(.046)$ & $(.046)$ & $(.042)$ \\
\hline Disorder & -.018 & -.019 & -.091 & -.111 \\
\hline & $(.075)$ & $(.075)$ & $(.080)$ & $(.079)$ \\
\hline Networks/exchange & .020 & .017 & .097 & .112 \\
\hline & $(.058)$ & $(.058)$ & $(.066)$ & $(.067)$ \\
\hline Tolerance of risk behavior & - & -.026 & -.032 & -.022 \\
\hline & & $(.046)$ & $(.047)$ & $(.046)$ \\
\hline Anomie & - & .072 & .079 & .100 \\
\hline & & $(.050)$ & $(.050)$ & $(.052)$ \\
\hline Collective efficacy & - & - & $-.155^{*}$ & $.136^{*}$ \\
\hline & & & $(.071)$ & $(.063)$ \\
\hline Intercept & $-1.552 * *$ & $-1.552 * *$ & $-1.558 * *$ & $-1.453 * *$ \\
\hline & $(.058)$ & $(.058)$ & $(.058)$ & $(.054)$ \\
\hline Intercept variance component & .027 & .024 & .003 & .003 \\
\hline
\end{tabular}

$* p<.05 ; * * p<.01$ (two-tailed tests). Standard errors in parentheses.

Note: Neighborhood $\mathrm{N}=339$; Individual $\mathrm{N}=3,272$. 
This finding is at odds with a number of recent studies that demonstrate the unique impact of poverty on health after controlling for individual factors (Kawachi, Kennedy, Lochner, and Prothrow-Stith 1997; Malmstrom, Sundquist, and Johansson 1999; Robert 1999).

Second, in contrast to the effect of poverty, we find that a measure of neighborhood affluence exerts unique protective effects on health, independent of individual factors and neighborhood structural controls. The effect of affluence, by comparison with poverty, indicates that the prevalence of middle and upper middle class residents in urban communities is an important structural factor influencing healthpromoting conditions. These data suggest that measures of the proportion of residents who are poor in a neighborhood may be capturing, in part, the influence of the absence of residents with resources. Consistent with Wilson's emphasis on the potentially detrimental effects of constrained mobility in disadvantaged urban neighborhoods, affluence conditioned the effect of residential stability. In neighborhoods with low levels of affluence, stability increases the likelihood of poor health. This effect declines, however, as affluence increases. This finding is consistent with other recent research demonstrating the conditional effects of residential stability on health outcomes (Ross, Reynolds, and Geis 2000) and calls attention to the detrimental consequences of combining sustained immobility with the absence of middle-class residents. The latter may have the social and economic resources with which to sustain local institutions, benefiting the neighborhood as a whole.

Third, the association between individual level African-American race/ethnicity and poor health was substantially reduced when affluence was controlled, though unaffected by inclusion of our measure of neighborhood poverty. Consistent with previous research exploring the impact of affluence on race differences in health among the elderly (Cagney, Browning, and Wen 2002), this finding suggests that models linking individual measures of disadvantage with health outcomes must simultaneously consider the prevalence of advantage in the environment with which individual level factors may be confounded. A simple assumption that race is confounded with the prevalence of poverty ignores the multiple dimensions of neighborhood economic structure that may be relevant for health outcomes.

Fourth, tests of the mechanisms hypothesized to link neighborhood structure with health resulted in a significant effect only for a measure of collective efficacy. Though a number of researchers have hypothesized that beneficial social ties at the neighborhood level will have consequences for community health, we found no direct effect of a measure of social support and sociability on self-rated health. Tests of the impact of subculture on health also yielded no unique effects of neighborhood level measures of anomie and tolerance for deviant behavior. This might be expected to the extent that we control for the effects of individual level health-risk behaviors on self-rated health-a key individual level mechanism through which the effects of neighborhood health-related subcultures are hypothesized to flow. Even before including individual controls for health risk behavior, however, subcultural measures were not significantly predictive of self-rated health-only anomie achieved marginal significance in the absence of health background controls. Although these analyses offer little support for hypotheses regarding subcultural influences on health, more effective measurement of the situational and group basis of alternative cultural orientations (as opposed to aggregated survey-based assessments of individual attitudes) may yield different findings.

The impact of collective efficacy may be channeled through a number of mechanisms. First, collective efficacy may orient neighborhood residents to the well-being of other members of the community. As Putnam (2000) has noted, strong attachments to community increase the likelihood that indicators of health problems may receive notice (e.g., a community member who is missing from church or a local meeting is more likely to elicit the concern of neighbors). Moreover, sentiments of solidarity and trust may lead community members to act on others behalf independently of a prior network tie. Second, the psychosocial benefits of trust may reduce stress and facilitate use of local space for recreational and exercise purposes. Indeed, some have found that the perception of social support (more directly related to the concept of trust) is more strongly associated with health than actual 
social support (Dunkel-Schetter and Bennett 1990).

Third, as some have argued, collective efficacy may signal a community's capacity to mobilize on behalf of a wide range of important neighborhood goals (Sampson, Raudenbush, and Earls 1997). This capacity may extend to the provision of high quality health care and health-relevant services. Mobilization capacity may also foster access to resources outside the neighborhood that aid in correcting local physical hazards such as infrastructural decay (abandoned buildings, crumbling sidewalks, inadequate traffic signage, etc.). The quality and availability of health services and extra-community resources may be a critical pathway through which neighborhood collective efficacy operates. Indeed, this pathway may also account, in part, for the robust effect of neighborhood affluence on health.

The study was not without limitations. First, our sample is restricted to the city of Chicago. While the data provide an unprecedented opportunity to consider the influence of both neighborhood structural and social process measures on health, our capacity to generalize from the analyses is limited. Multiple city or national samples would also likely capture greater variation across neighborhoods in the health of residents. Second, our individual level data are cross-sectional. Despite relatively extensive health controls, we are still unable to rule out selection as a confounding process in the association between neighborhood factors and health. Third, though our measure of collective efficacy is purged of its association with individual level social support and sociability, we were not able to include a comparable individual level control derived directly from the MCIC-MS data. Moreover, the collective efficacy measure does not capture actual instances of action on behalf of community goals, but rather the perception that such action would be taken under certain conditions. Finally, we consider the effects of neighborhood characteristics on a single indicator of self-rated health status; the effects of neighborhood structure and social process measures may differ by the specific health outcome considered.

Future research will hopefully clarify a number of outstanding questions accompanying or motivated by these analyses. First, the impact of objective measures of medical infrastructure on health may contribute to the explanatory power of models that include neighborhood effects. The capacity to attract and support local medical facilities, as noted, may be associated with both affluence and collective efficacy and potentially mediate some proportion of their effects on individual health. Second, employing longitudinal data on health outcomes will provide an opportunity both to establish the causal influence of neighborhood factors with more certainty and to tease out the indirect pathways - both individual and neighborhood level-through which neighborhoods operate to affect health. Third, national data on neighborhood characteristics and multiple health outcomes will allow for generalizable conclusions and more precise (and simultaneous) estimation of the unique effects of dimensions of neighborhood structure (e.g., poverty and affluence). These findings and the results of future analyses will add to our accumulating knowledge regarding the significance of macro structural characteristics and social processes for the spatial organization of health.

\section{Appendix. Correlations Among Neighborhood Level Variables in the Analysis $(N=339)$}

\begin{tabular}{|c|c|c|c|c|c|c|c|c|c|c|c|c|}
\hline Variables & 1 & 2 & 3 & 4 & 5 & 6 & 7 & 8 & 9 & 10 & 11 & 13 \\
\hline 1. Total population & 1.000 & & & & & & & & & & & \\
\hline 2. Residential stability & -.153 & 1.000 & & & & & & & & & & \\
\hline 3. Immigrant concentration & -.040 & -.212 & 1.000 & & & & & & & & & \\
\hline 4. Poverty & -.229 & -.303 & -.111 & 1.000 & & & & & & & & \\
\hline 5. Affluence & .276 & .366 & -.120 & -.768 & 1.000 & & & & & & & \\
\hline 6. Stability*Affluence & -.179 & .463 & -.008 & -.057 & .190 & 1.000 & & & & & & \\
\hline 7. Neighborhood health ('92-'94) & -.094 & -.020 & -.037 & .055 & -.136 & .047 & 1.000 & & & & & \\
\hline 8. Networks/exchange & -.028 & .169 & .021 & -.024 & .302 & .176 & -.008 & 1.000 & & & & \\
\hline f risk behavior & -.004 & -.181 & -.067 & .076 & -.072 & -.130 & -.118 & .078 & 1.000 & & & \\
\hline 10. Subcultural cynicism & -.018 & .033 & .105 & .093 & -.181 & -.019 & .026 & .034 & .055 & 1.000 & & \\
\hline 11. Disorder & -.199 & -.290 & .114 & .773 & -.766 & -.142 & .058 & -.243 & .107 & .148 & 1.000 & \\
\hline 12. Collective efficacy & .019 & .309 & -.116 & -.418 & .537 & .202 & .038 & .599 & -.079 & -.025 & -.583 & 1.000 \\
\hline
\end{tabular}




\section{NOTES}

1. Like the original social disorganization perspective, the collective efficacy approach was conceived to explain variations in neighborhood crime rates. Therefore, collective efficacy with respect to the control of neighborhood crime should not be seen as necessarily equivalent to the community capacity to promote health. At the same time, evidence suggests that collective efficacy is a generalizable resource capable of influencing a wide range of outcomes including self-reported physical health (Browning and Cagney 2002) and violence between intimate partners (Browning 2002).

2. Respondents were given the following definition of "neighborhood:" "By neighborhood ... . we mean the area around where you live and around your house. It may include places you shop, religious or public institutions, or a local business district. It is the general area around your house where you might perform routine tasks, such as shopping, going to the park, or visiting with neighbors."

3. The response rate for the PHDCN-CS was $75 \%$.

4. The response rate for the MCIC-MS averaged around $55 \%$ across the 10 cross-sectional samples. Because the MCIC-MS did not achieve as high a response rate as the PHDCN-CS, we compared the latter with combined 1993, '94, '95, and '96 MCICMS samples. The distributions across basic demographic characteristics (gender, age, and race) were quite similar.

5. We also investigated the possibility that the relationship between self-rated health and other health outcomes varied by neighborhood (calling into question efforts to explain variation in self-rated health across context). A series of random slope models examining potential variation in the relationship between self-rated health and selfreports of having ever been told by a doctor that the respondent has asthma, a heart condition, or high cholesterol offered no evidence of significant variability in slope coefficients across neighborhoods.

6. The well known problem of collinearity among macro level indicators of socioeconomic status, including income, education, and occupational status, renders their unique effects difficult to assess in multivariate models. This problem has led some to argue for the use of factor analytic approaches - a strategy we employ for the measurement of residential stability and ethnic heterogeneity. Because we are concerned with the comparative effects of poverty and affluence, however, we chose to focus on single item measures of economic status in order to avoid complicating interpretation of their relative effects on health.

7. The analysis employed alpha-scoring factor analysis with an oblique rotation. Scores from principal components analyses yielded the same pattern of effects in multivariate analyses of health.

8. Eigenvalues for the two factors exceeded 1.

9. Though our measure of collective efficacy does not directly tap instances of prosocial action on behalf of the health of local residents, this approach to measuring collective efficacy is likely to be highly correlated with health problems that spur action. To the extent that these precipitating health problems are differentially distributed across neighborhoods, actual mobilization to address them may be confounded with poor health. One approach to measuring action on behalf of community health would be to measure neighborhood responses to exogenous health shocks to which all communities are exposed (Klinenberg 2002).

10. Distinct from individual level reliability (e.g, Cronbach's alpha), the reliability of neighborhood level scale scores is dependent upon both the sample size within the neighborhood as well as the proportion of the total variance that is between (vs. within) neighborhoods. The reliability estimates of neighborhood scales are comparable to reliabilities reported in other recent neighborhood research (see Sampson, Morenoff, and Earls 1999).

11. Response categories for the latter four items were "never, rarely, sometimes, or often."

12. We investigated whether the effects of individual level covariates varied across neighborhoods by examining a series of random slope models. Tests of significance on variance components for random slopes offered no evidence of significant 
variability in the effects of individual level covariates across neighborhoods.

13. While we report the intercept variance across models, these estimates should be interpreted with caution. The increase in the variance component with the addition of neighborhood level predictors, for instance, implies an impossibility-i.e., that the percentage of variance explained has actually decreased across more fully specified models. Volatility in the estimate of the variance component, however, can occur when the residual variance at the neighborhood level is low (Snijders and Boskers). Rather than rely on intercept variance estimates and associated significance tests, we focus on more powerful tests of theoretically relevant coefficients.

14. The spatial clustering of self-reported health at the neighborhood level led us to investigate the possibility that spatial dependency was operating in the data. A Moran's I test for spatial correlation in the residuals (Anselin 1988) from Model 3 of Table 3, however, was not significant ( $\mathrm{p}>$ $.05)$. Dummy variables indicating region of the City (north, west, and south-corresponding to major ethnic/racial divisions within the city) were also not significant predictors of self-rated health.

15. Entering demographic characteristics by stages indicates that race/ethnicity and education account for the association between neighborhood poverty and selfrated health.

16. We examined the interaction between poverty and stability separately. The coefficient was not significant.

17. Substituting, as measures of neighborhood affluence, the percentage college educated in the neighborhood and (separately) a composite index of education and income yield the same pattern of interaction with residential stability in comparable multivariate analyses of fair or poor self-rated health.

18. Though we include the prior neighborhood health measure to account, in part, for any possible endogeneity of neighborhood characteristics, models with and without this control result in negligible changes in coefficient magnitudes and significance levels.

\section{REFERENCES}

Andersen, Ronald M., Aday,L.A., Lyttle, C.S., Cornelius, L.J., \& Chen, M.-S. 1987. Ambulatory Care and Insurance Coverage in an Era of Constraint. Chicago: Pluribus Press.

Anderson, Elijah. 1990. Streetwise. Chicago: University of Chicago Press.

Anselin, Luc. 1988. Spatial Econometrics: Methods and Models. Dordrecht, Germany: Kluwer Academic.

Benyamini, Y. and E. L. Idler. 1999. "Community Studies Reporting Asssociation Between SelfRated Health and Mortality." Research on Aging 21:477-500.

Berkman, Lisa F. 1995. "The Role of Social Relations in Health Promotion." Psychosom Med 57:245-54.

Berkman, Lisa F. and L. Breslow. 1983. Health and Ways of Living. New York: Oxford University Press.

Berkman, Lisa F., Thomas Glass, Ian Brissette, and Teresa E. Seeman. 2000. "From Social Integration to Health: Durkheim in the New Millennium." Social Science \& Medicine 51:843-57.

Berkman, Lisa F. and S. L. Syme. 1979. "Social Networks, Host Resistance and Mortality: A Nine Year Follow-up Study of Alameda County Residents." American Journal of Epidemiology 109:186-204.

Blair, Steven N., Harold W. Kohl III, Ralph S. Paffenbarger, Debra G. Clark, Kenneth H. Cooper, and Larry W. Gibbons. 1989. "Physical Fitness and All-Cause Mortality." Journal of the American Medical Association 262:2395-2401.

Browning, C. R. 2002. "The Span of Collective Efficiency: Extending Social Disorganization Theory to Partner Violence." Journal of Marriage and the Family 64(4):833-50.

Browning, C. R. and K. Cagney. 2002. "Collective efficacy and health: neighborhood social capital and self-rated physical functioning in an urban setting." Journal of Health and Social Behaviors 43(4):383-99.

Bryk, Anthony S. and Stephen W. Raudenbush. 1992. Hierarchical Linear Models: Applications and Data Analysis Methods. Newbury Park, N.J.: Sage.

Bursik, Robert J. 1988. "Social Disorganization and Theories of Crime and Delinquency: Problems and Prospects." Criminology 26:519-51.

Cagney, K., C. R. Browning, and M. Wen. 2002. "Race and self-rated health at older ages: what difference does the neighborhood make?" Unpublished manuscript.

Davey Smith, G., C. Hart, G. Watt, D. Hole, and V. Hawthome. 1998. "Individual social class, areabased deprivation, cardiovsculardisease risk factors, and mortality: the Renfrew and Paisley 
study." Journal of Epidemiology Community Health 52:399-405.

Diez-Roux, A. V., F. J. Nieto, C. Muntaner, H. A. Tyroler, G. W. Comstock, E. Shahar, L. S. Cooper, R. L. Watson, and M. Szklo. 1997. "Neighborhood environments and coronary heart disease: a multilevel analysis." American Journal of Epidemiology 146:48-63.

Duncan, Greg J. and Stephen Raudenbush. 1999. "Assessing the Effects of Context in Studies of Child and Youth Development." Educational Psychologist 34:29-41.

Dunkel-Schetter, C. and T. L. Bennett. 1990. "Differentiating the cognitive and behavioral aspects of social support.' Pp. 267-96 in Social Support: An Interactional View, edited by B. R. Sarason, I. G. Sarason, and G. R. Pierce. New York: John Wiley.

Durkheim, Emile. 1979. Suicide. New York, NY: The Free Press.

Ecob, R. 1996. "A multilevel modeling approach to examining the effects of area of residence on health and functioning." $J R$ Stat Soc A 159:61-75.

Ferraro, K. F., M. M. Farmer, and J. A. Wybraniec. 1997. "Health Trajectories: Long-Term Dynamics Among Black and White Adults." Journal of Health and Social Behavior 38:38-54.

Finch, B.K., RA Hummer, M Reindel, and WA Vega. 2002."Validity of self-rated health among Latino(a)s." American Journal of Epidemiology 155:755-59.

Fitzpatrick, K. and M. Lagory. 2000. Unhealthy Places: the Ecology of Risk in the Urban Landscape. New York: Routledge.

Gibson, RC. 1991. "Race and the self-reported health of elderly persons." Journal of gerontology: Social Sciences 46:S235-42.

Goldstein, MS, JM Siegel, and R Boyer. 1984. "Predicting Changes in Perceived Self-Reported Health Status." American Journal of Public Health 74:611-14.

Haan, M., G.A. Kaplan, and T. Camacho. 1987. "Poverty and health: prospective evidence from the Alameda County Study." American Journal of Epidemiology 125:989-98.

Hawe, Penelope and Alan Shiell. 2000. "Social Capital and Health Promotion: A Review." Social Science \& Medicine 51:871-85.

House, J.S., K.R. Landis, and D. Umberson. 1988. "Social Relationships and Health." Science 241:540-45.

House, J.S., C. Robbins, and H.L. Metzner. 1982. "The Association of Social Relationshipsand Activities with Mortality: Prospective Evidence from the Tecumseh Community Health Study." American Journal of Epidemiology 116:123-40.

House, James. 1981. Work Stress and Social Support. Reading, MA: Addison-Wesley.

Humphreys, K. and R. Carr-Hill. 1991. "Area varia- tions in health outcomes: artefact or ecology." International Journal of Epidemiology 20:251-58.

Idler, E. L. and R. J. Angel. 1990. "Self-rated Health and Mortality in the NHANES-1 Epidemiologic Follow-up Study." American Journal of Public Health 80:446-52.

Idler, E. L. and Y. Benyamini. 1997. "Self-Rated Health and Mortality: A Review of TwentySeven Community Studies." Journal of Health and Social Behavior 38:21-37.

Idler, E. L. and S. Kasl. 1995. "Self-Ratings of Health: Do They Also Predict Change in Functional Ability." Journal of Gerontology: Social Sciences 50B:S344-S353.

Johnson, RJ and FD Wolinsky. 1994. "Gender, race, and health: The structure of health status among older adults." The Gerontologist 34:24-35.

Jones, K. and C. Duncan. 1995. "Individuals and their ecologies: analyzing the geography of chronic illness within a multilevel modelling framework." Health \& Place 1:27-40.

Kaplan, G, V. Barell, and A. Lusky. 1988. "Subjective State of Health and Survival in Elderly Adults." Journal of Gerontology: Social Sciences 43:S114-120.

Kaplan, G, W. J. Strawbridge, T. Camacho, and R. Cohen. 1993. "Factors Associated with Change in Physical Functioning in the Elderly: A SixYear Prospective Study." Journal of Aging and Health 5:40-53.

Kasarda, J. D. and M. Janowitz. 1979. "Community Attachment in Mass Society." American Sociological Review 39:329-39.

Katz, Lawrence F., Jeffrey R. Kling, and Jeffrey B. Liebman. 2001. "Moving to opportunity in Boston: Early results of a randomized mobility experiment." Quarterly Journal of Economics 116:607-54.

Kawachi, I and Lisa F. Berkman. 2000. "Social Cohesion, Social Capital, and Health." in Social Epidemiology, edited by L. F. Berkman and I. Kawachi. Oxford: Oxford University Press.

Kawachi,-I, B.P. Kennedy, K. Lochner, and D. Prothrow-Stith. 1997. "Social Capital, Income Inequality, and Mortality." American Journal of Public Health 87:1491-98.

Klinenberg,Eric. 2002. Heatwave: A SocialAutopsy of Disaster in Chicago. Chicago: The University of Chicago Press.

Kornhauser, Ruth Rosner. 1978. Social Sources of Delinquency. Chicago: University of Chicago Press.

Krieger, N. 1992. "Overcoming the absence of socioeconomic data in medical records: validation and application of a census-based methodology." American Journal of Public Health 82:703-10.

LeClere, Felicia B., Richard G. Rogers, and Kimberley Peters. 1997. "Ethnicity and mortali- 
ty in the United States: individual and community correlates." Social Forces 76:169-367.

. 1998. "Neighborhood Social Context and

Racial Differences in Women's Heart Disease Mortality." Journal of Health and Social Behavior 39:91-107.

Leventhal, Tama and Jeanne Brooks-Gunn. 2001. "Moving to Opportunity: An experimental study of neighborhood effects on mental health." Unpublished manuscript.

Malmstrom, Marianne, Jan Sundquist, and SvenErik Johansson. 1999. "Neighborhood Environment and Self-Reported Health Status: A Multilevel Analysis." American Journal of Public Health 89:1181-86.

Mossey, J.M., \& Shapiro, E. (1982). Self-rated health: a predictor of mortality among the elderly. American Jounal of Public Health, 72, 800-08.

Orth-Gomer, K. and J. Johnson. 1987. "Social Network Interaction ande Mortality: A Six Year Follow-up of a Random Sample of the Swedish Population." J Chronic Dis 40:949-57.

Paffenbarger, Ralph S., Robert T. Hyde, Alvin Wing, I-Min Lee, Dexter L. Jung, and James Kampert. 1993. "The Association of Chagnes in PhysicalActivity Level and Other Lifestyle Characteristics with Mortality Among Men." New England Journal of Medicine 329, 538-45.

Putnam, Robert. 2000. Bowling Alone: The Colapse and Revival of American Community. New York: Simon \& Schuster.

Raudenbush, Stephen W. and Anthony S. Bryk. 2002. Hierarchical Linear Models: Applications and Data Analysis Methods. Thousand Oaks, NJ: Sage.

Robert, Stephanie A. 1998. "Community-level socioeconomic status effects on adult health." Journal of Health and Social Behavior 39:18-37.

- 1999. "Socioeconomic Position and Health: The Independent Contribution of Community Socioeconomic Context.' Annual Review of Sociology 25:489-516.

Rook, K.S. 1990. "Social Relationships as a Source of Companionship: Implications for Older Adults' Psychological.” Pp. 221-50 in Social Support: An Interactional View, edited by B. R. Sarason, T. G. Sarason, and G. R. Pierce. New York: John Wiley.

Ross, C.E. and J. Mirowsky. 2001. "Neighborhood Disadvantage, Disorder, and Health." Journal of Health and Social Behavior 42:258-76.

Ross, C.E., J. R. Reynolds, and K. J. Geis. 2000. "The Contingent Meaning of Neighborhood Stability for Residents; Psychological Wellbeing." American Sociological Review 65: 587-97.
Sampson, Robert J. 1997. "The Embeddedness of Child and Adolescent Development: A Community-Level Perspective on Urban Violence." Pp. 31-77 in Violence and Childhood in the Inner City, edited by J. McCord. Cambridge: Cambridge University Press.

Sampson, Robert J. and Dawn Jeglum Bartusch. 1998. "Legal Cynicism and (Subcultural?) Tolerance of Deviance: The Neighborhood Context of Racial Differences." Law \& Society Review 32:777-804.

Sampson, Robert J., Jeffrey D. Morenoff, and Felton Earls. 1999. "Beyond Social Capital: Spatial Dynamics of Collective Efficacy." American Sociological Review 64:633-60.

Sampson, Robert J. and Stephen W. Raudenbush. 1999. "Systematic Social Observation of Public Spaces: A New Look at Disorder in Urban Neighborhoods." American Journal of Sociology 105:603-52.

Sampson, Robert J., Stephen W. Raudenbush, and Felton Earls. 1997. "Neighborhoods and Violent Crime: A Multilevel Study of Collective Efficacy." Science 227:918-23.

Shaw, Clifford R. and Henry D. McKay. 1969. Juvenile Delinquency and Urban Areas. Chicago: The University of Chicago Press.

Sloggett, A. and H. Joshi. 1994. "Higher mortality in deprived areas: community or personal disadvantage?" BMJ 309:1470-74.

Snijders, Tom and Roel Bosker. 1999. Multilevel Analysis: An Introduction to Basic and Advanced Multilevel Modeling. London: Sage.

Waitzman, N.J. and K.R. Smith. 1998. "Phantom of the area: poverty-area residence and mortality in the United States." American Journal of Public Health 88:973-76.

Wilson, IB and S Kaplan. 1995. "Clinical Practice and Patient's Self-Reported Health Status: How are the Two Related?" Medical Care 33(suppl):S209-S214.

Wilson, William J. 1987. The Truly Disadvantaged: The Inner City, the Underclass, and Public Policy. Chicago: University of Chicago Press.

IIAl 1996. When Work Disappears. New York: Alfred A. Knopf.

Wolinsky, Fredric D, and William M. Tierney. 1998. "Self-rated health and adverse health outcomes: An exploration and refinement of the trajectory hypothesis." Journal of Gerontology: Social Sciences 53B(6): S336-S340.

Yen, IH and GA Kaplan. 1999. "Neighborhood social environment and risk of death: multilevel evidence from the Alameda County Study." American Journal of Epidemiology 151:1132-33. 
Christopher R. Browning is Assistant Professor of Sociology at the Ohio State University. His research interests include the effects of community structural disadvantage and social organization on risk behavior and health; the life-course consequences of childhood maltreament; and multilevel modeling techniques.

Kathleen A. Cagney is an Assistant Professor in the Department of Health Studies at the University of Chicago. Her research interests include access to and quality of long-term care arrangements, particularly race/ethnic and socioeconomic status differences; demography of aging, especially the role of family structure in the timing of long-term care use; the effects of education and wealth on cognitive change at older ages; life course approaches to research in health and aging; neighborhood and health; social survey methodology and health status assessment.

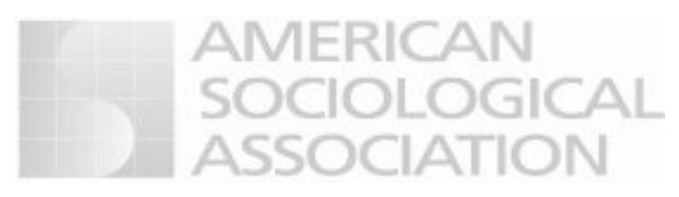

